\title{
Conflictos y armonías de la modernización cultural en un espacio local. La profesionalización del periodismo durante las primeras décadas del siglo xx en Bahía Blanca (Argentina)
}

\section{Conflicts and Harmonies of Cultural Modernization in a Local Space. The Professionalization of Journalism During the Early Decades of the 20th Century in Bahía Blanca (Argentina)}

\author{
María de las Nieves Agesta \\ (D) https://orcid.org/0000-0002-0586-1008 \\ Conicet-Universidad Nacional del Sur \\ Centro de Estudios Regionales "Prof. Félix Weinberg", Argentina \\ nievesagesta@uns.edu.ar
}

Resumen: El presente artículo analiza el proceso de profesionalización del periodismo en Bahía Blanca, una ciudad intermedia del interior de la Argentina, a partir de la reconstrucción de las experiencias de organización que congregaron a los trabajadores de la prensa durante las tres primeras décadas del siglo xx. El fracaso de los sucesivos proyectos y su efímera existencia, permiten sostener que estos intentos de institucionalización estuvieron atravesa-

cómo citar: Agesta, M. de las N. (2019). Conflictos y armonías de la modernización cultural en un espacio local. La profesionalización del periodismo durante las primeras décadas del siglo xx en Bahía Blanca (Argentina). Secuencia (104), e1369. DoI: https://doi.org/10.18234/secuencia.v0i104.1369 
dos por múltiples contradicciones propias de las condiciones impuestas por la lejanía geográfica y las dimensiones de un campo cultural acotado e incipiente. Así, las tensiones entre las representaciones modernas y aristocráticas del ejercicio escriturario y entre las posibilidades reales del mercado cultural local y el horizonte de expectativas construido por los escritores, conspiraron contra la consolidación de una organización gremial estable que articulara las demandas de los periodistas.

Palabras clave: prensa; profesionalización; asociaciones; modernización; Bahía Blanca.

Abstract: This article analyzes the process of professionalizing journalism in Bahía Blanca, a medium-sized Argentinian city, based on the reconstruction of the organizational experiences of press workers during the first three decades of the $20^{\text {th }}$ century. The failure of successive projects and their shortlived existence shows that these institutionalization attempts were marked by several contradictions relating to the conditions imposed by the geographical distance and the dimensions of a constrained and incipient cultural field. Thus, tensions between the modern and aristocratic representations of the writing exercise, and the real possibilities of the local cultural market and the horizon of expectations defined by authors, conspired against the consolidation of a stable guild organization that would express journalists' demands.

Key words: press; professionalization; associations; modernizations; Bahía Blanca.

Fecha de recepción: Fecha de aceptación:

18 de abril de $2016 \quad 24$ de noviembre de 2016

I a profesionalización de la escritura y la configuración de un campo inLtelectual en la Argentina fueron el resultado de un desarrollo complejo y contradictorio que, como señalan Carlos Altamirano y Beatriz Sarlo (1997, pp. 161-201), formó parte del proceso más amplio de modernización que se 
estaba produciendo en la sociedad nacional. ${ }^{1}$ Habiéndose iniciado a fines del siglo xIx, la transformación de los gentlemen escritores en profesionales (Viñas, 1995) alcanzó su primera concreción en torno al año 1910 a partir de la creciente diferenciación de la actividad intelectual respecto de la esfera de lo político, de la aparición de ideologías de artista que funcionaron como nuevos discursos de legitimación, de la consolidación de formas inéditas de iniciación cultural, del surgimiento de espacios y modos de sociabilidad innovadores $y$, sobre todo, de la emergencia de una identidad social definida por el ejercicio de la escritura. Con esta concepción "no-economicista", Altamirano y Sarlo pretenden explicar las particularidades que el proceso asumió en un país periférico como la Argentina donde, a pesar de las limitadas posibilidades de subsistencia que ofrecía la práctica literaria en el contexto de un merca-

${ }^{1}$ Si bien no pretendemos ahondar en los extensos debates que se han planteado en torno a los conceptos de modernización y de modernidad tal como hemos hecho en otras ocasiones (Agesta, 2016), cabe señalar que retomamos aquí la propuesta de Renato Ortiz (2000) que considera la modernidad, además de como un tipo de organización social, como una narrativa, "una concepción del mundo que se articula con la presencia real o idealizada de elementos diversos: urbanización, tecnología, ciencia, industrialización, etc.", que configuró un conjunto de patrones y referencias que orientaron las conductas y las aspiraciones de los individuos. De esta manera, lo moderno se presenta como un horizonte de expectativas, siempre inacabado, que anudó proyecto y trayectoria en determinados contextos situados y que no debe confundirse con una de sus realizaciones históricas, la europea, tampoco uniforme y monolítica. De acuerdo con ello, se compusieron los programas de modernización que dieron origen a la "vorágine de la vida moderna" alimentada, como sostiene Marshall Berman (2006), por los grandes descubrimientos de las ciencias físicas, la industrialización de la producción, las alteraciones demográficas, los sistemas de comunicación de masas, los movimientos sociales masivos de personas y pueblos, y la inserción y el mantenimiento de todas las personas e instituciones en "un mercado capitalista mundial siempre en expansión y drásticamente fluctuante". Dichos programas, más allá de sus limitaciones y contradicciones, se sostuvieron sobre una concepción del tiempo lineal y evolutiva fundada en la idea de progreso que incluía dimensiones materiales, sociales y culturales. Parte de este proceso fue la especialización y autonomización de las distintas esferas de lo real a partir de la consolidación de criterios, pautas y prácticas diferenciadas. En la Argentina, al igual que en el resto de los países latinoamericanos, la modernización se produjo en el marco de su incorporación como naciones exportadoras de productos primarios al mercado capitalista internacional en condiciones sumamente distintas respecto de aquellas de los estados industriales que estudia Berman. Por esta razón, las formas que asumieron estos procesos requieren de un análisis específico que no adhiera de manera irreflexiva a los postulados teóricos generados en las sociedades "centrales", tal como hicieron desde la sociología José J. Brunner (1986) y Néstor García Canclini (2005) y desde las letras, Ángel Rama (2004) y Julio Ramos (2003). Igualmente interesantes resultan trabajos como el de Waldo Ansaldi (1996-1997) donde, a propósito de la provincia de Córdoba, se plantea el problema de la modernidad y sus limitaciones en los espacios provincianos de la Argentina. 
do editorial relativamente reducido, surgió durante las primeras décadas del siglo una nueva conciencia profesional entre los "trabajadores de la pluma".

Dichos inconvenientes no eran prerrogativa de los países latinoamericanos ya que, como sostiene Pierre Bourdieu (1995), quienes reivindicaban la profesión de escritor "demasiado a menudo, sólo puede asumir la función que ellos consideran principal a condición de tener una profesión secundaria de la que sacan sus ingresos principales" (p. 336). La autonomización de la escritura, sin embargo, parece haber encontrado límites más estrechos en América Latina, donde la posición de los escritores se ubicó siempre en la tensión entre la autonomía relativa que le otorgaba la posesión de un saber específico y de sus propios mecanismos de consagración y legitimación, y la dependencia respecto de las fuerzas políticas y económicas. En efecto, las relaciones con el Estado y con el mercado permearon, a decir de Julio Ramos (2003) y Ángel Rama (2004), el accionar y las representaciones de los intelectuales de la región desde sus orígenes dando lugar a un proceso de modernización desigual en el cual convivían la voluntad de autonomización con "las condiciones de imposibilidad de su institucionalización" (Ramos, 2003, p. 12. Cursivas del original). En Buenos Aires, la vocación autonómica y la conciencia profesional se concretaron en vísperas del centenario de la Revolución de Mayo en reclamos corporativos, como los formulados por Roberto J. Payró, ${ }^{2}$ que se materializaron con la aprobación de la Ley de Propiedad Intelectual (1910) y con la fundación de las primeras organizaciones de escritores. ${ }^{3}$ Para entonces, los periodistas ya habían realizado sus primeras tentativas de asociación gremial -bajo la figura del "círculo"- y, poco después, ensayarían la redacción de un primer proyecto de estatuto profesional (1926). ${ }^{4}$

Lejos del mayor centro de realización y consumo cultural del país, los productores intelectuales del interior se veían sometidos a otras limitaciones

${ }^{2}$ El programa de Payró se centraba en la defensa de las editoriales nacionales, de los derechos de autor y del periodista, en la fundación de una sociedad de escritores, etc. (Altamirano y Sarlo, 1997).

${ }_{3}^{3}$ En 1906 se creó la primera Sociedad de Escritores presidida por Roberto Payró (cuya segunda fundación en 1928 dio origen a la Sociedad Argentina de Escritores); un año después se inauguró la Sociedad de Autores Dramáticos y Líricos y en 1910 se inició la Sociedad de Autores Dramáticos. De esta última agrupación se desprendió más tarde el Círculo Argentino de Autores y se conformó en 1934 la Sociedad General de Autores de la Argentina (Argentores) (Rivera, 1998, pp. 52-53).

${ }^{4}$ Dicho estatuto se concretaría recién en 1946 con la aprobación de la Ley 12.908 (Galván Moreno, 1944). 
impuestas por las condiciones de los -mucho más reducidos- mercados locales y regionales. Si bien el periodismo constituía también en la capital un ámbito de intervención y una fuente de ingresos privilegiados para los escritores, en ciudades como Bahía Blanca este era prácticamente el único medio posible para quienes pretendieran subsistir del ejercicio de la escritura. La brecha temporal que en Buenos Aires había separado la institucionalización de ambas esferas, se veía en este contexto ampliada de manera considerable a la par que se acentuaban las tensiones entre la dimensión de las representaciones y las de las prácticas. Aunque existieran grupos que, guiados por el ideal de autonomía, se definieran como "poetas" y se diferenciaran de los periodistas, ${ }^{5}$ fueron estos últimos quienes concretaron los primeros -y únicos en el periodo considerado- ensayos de asociación gremial de la labor intelectual. ${ }^{6} \mathrm{El}$ presente artículo se propone abordar estas experiencias de organización que congregaron a los trabajadores de la prensa en Bahía Blanca durante las tres primeras décadas del siglo xx y analizar su fracaso como factores exclusivos de nucleamiento de los primeros profesionales de la pluma en este periodo. En una ciudad intermedia ${ }^{7}$ del sudoeste de la provincia de Buenos Aires como la que nos ocupa, dicho proceso de institucionalización estuvo, a su vez, atravesado por múltiples contradicciones originadas en la convivencia de concepciones modernas y aristocráticas del ejercicio escriturario $y$, sobre todo, por el desfase entre el horizonte de expectativas que los escritores habían construido a partir de su contacto con intelectuales y centros de cultura nacionales e internacionales, $y$ la realidad impuesta por un campo cultural acotado e incipiente. ${ }^{8}$ De esta manera, el tratamiento de problemas generales en un

${ }^{5}$ Sobre las representaciones y autorrepresentaciones de los intelectuales locales, véase Agesta (2013a, pp. 310-335).

${ }^{6}$ Como señala Alejandra Laera (2008, pp. 495-522), al analizar el proceso de profesionalización de la escritura se ha equiparado la actividad periodística y la literaria. Sin embargo, y sobre todo a partir del centenario de la creciente especialización dentro del periodismo y las diferencias en los modos de acceso, las formas de agrupación y los vínculos con el mercado conllevarían una progresiva distinción entre ambas tareas.

${ }^{7}$ Utilizamos el concepto de ciudad intermedia tal como lo define Josep M. Llop Tomé (1999) para referirnos, no únicamente al número de habitantes, sino al papel y la función que la localidad cumple "en su territorio más o menos inmediato, la influencia y relación que ejerce y mantiene en este y los flujos y relaciones que genera hacia el exterior" (pp. 43-44).

${ }^{8}$ El presente trabajo se inserta en un proyecto más amplio centrado en el estudio de las revistas culturales editadas en Bahía Blanca entre 1902 y 1927. En tanto agentes y productos activos del proceso de modernización cultural que tuvo lugar en la ciudad desde las últimas décadas del siglo xix, estas publicaciones contribuyeron a configurar un campo periodístico 
ámbito provinciano permite revisar las hipótesis formuladas para dar cuenta del devenir capitalino. Frente a la abundante producción historiográfica que se ha ocupado del fenómeno en el escenario porteño, los estudios referidos a la profesionalización de los intelectuales del interior del país son todavía escasos o, incluso en casos como el de Bahía Blanca durante el periodo considerado, prácticamente inexistentes. ${ }^{9}$ En ese sentido, se procura contribuir a la construcción de una historia cultural más plural y compleja que tome en cuenta la diversidad del territorio nacional y relativice los relatos homogeneizadores propuestos desde los centros. Más que un intento por abordar el devenir sindical del sector, este trabajo pretende recuperar las experiencias de asociativismo ocupacional que fortalecieron la cohesión de los periodistas bahienses mediante la definición paulatina de una identidad y de intereses compartidos. En este sentido, y debido a la concepción misma de la tarea de escritura, la historia gremial se articula con la cuestión de la sociabilidad intelectual en tanto la organización laboral supuso el reconocimiento mutuo a partir del ejercicio de una práctica ligada a la distinción social y cultural que brindaba la vinculación con el mundo letrado.

\section{PERIODISMO Y PERIODISTAS EN BAHÍA BLANCA A PRINCIPIOS DEL SIGLO XX}

Fundada como fortaleza en 1828, Bahía Blanca se estaba convirtiendo a principios del siglo xx en un centro regional para el sur de la provincia de Buenos Aires y para la zona norte de la Patagonia. Su constitución como nodo ferroportuario ${ }^{10}$ en la década de 1880 había impulsado el crecimien-

complejo participando en el proceso de profesionalización de los trabajadores gráficos y literarios, en la conformación de grupos y modos de acción cultural y en la construcción de valores e instancias de legitimación específicos (Agesta, 2016).

${ }^{9}$ Entre ellos, pueden mencionarse los trabajos compilados por Paula Laguarda y Flavia Fiorucci (2012), por Flavia Fiorucci (2013) y por Ana Clarisa Agüero y Diego García (2010), así como las contribuciones de Ana Teresa Martínez (2013) a propósito de Santiago del Estero, de Ricardo Pasolini (2006) sobre la localidad de Tandil, de Soledad Martínez Zuccardi (2012) sobre Tucumán, y de Ezequiel Grisendi (2014) respecto de la ciudad de Córdoba.

${ }^{10}$ La extensión de las vías férreas de la empresa del Ferrocarril Sud hasta Bahía Blanca en 1884 y la apertura del puerto de aguas profundas en sus inmediaciones permitieron la incorporación de la ciudad a la economía nacional como nodo comercial orientado a la exportación de productos agropecuarios. Durante los años subsiguientes se establecieron también otras compañías ferroviarias, como la del Ferrocarril Bahía Blanca al Noroeste (1887) y la del Ferrocarril 
to exponencial de la población -ligado a la gran afluencia inmigratoria- ${ }^{11}$ y la economía locales en tanto implicaba su inserción exitosa en el modelo agroexportador encabezado a nivel nacional por la denominada Generación del $80 .{ }^{12} \mathrm{El}$ progreso, tal como era entendido entonces, requería sin embargo del concurso, no sólo de factores materiales, sino igualmente de otros de orden social e intelectual que ocuparon la atención de hombres y mujeres de la época (Cernadas de Bulnes, 1995, pp. 35-62). En los aspectos educativos y culturales, la expansión fue notable y se centró en la multiplicación de instituciones, formaciones y agentes. Los profesionistas liberales llegados a principios del siglo a partir de la instalación de los tribunales federales (1902) y de los tribunales provinciales Costa Sud (1905), activaron prácticas culturales, asociaciones y proyectos modernos acordes con su voluntad de recusar la representación de "ciudad fenicia" atribuida a la ciudad. La ocupación de posiciones directivas en entidades ya prestigiosas como la Asociación Bernardino Rivadavia (1882) acompañó, entonces, la fundación de otras nuevas como la Asociación Cultural (1919) y la revitalización de la actividad teatral, artística y literaria de la ciudad.

En este marco, el periodismo local se presentó como signo, marca y agente del progreso. La proliferación y diversificación de los medios impresos formaron parte activa del programa modernizador que llevaron adelante los grupos letrados, en el cual confluyeron factores tecnológicos, económi-

Rosario-Puerto Belgrano (1923), y se instalaron nuevos puertos, como Galván en 1905, Arroyo Pareja en 1908 y el Militar en 1901. El movimiento económico generado a partir de la ubicación estratégica de la localidad y de esta ampliación infraestructural, impulsó un desarrollo simbiótico entre el hinterland rural y el núcleo urbano. La ciudad fue conformando, de este modo, una estructura comercial, industrial, financiera y de servicios en expansión que constituyó un factor de atracción poblacional y el fundamento de sus aspiraciones de centralidad regional y de crecimiento futuro (Silva, 1988, pp. 229-243).

${ }^{11}$ De acuerdo con los censos nacionales, la población del partido de Bahía Blanca pasó de tener 1472 hab. en 1869 a 14238 hab. en 1895 y 70269 hab. en 1914, hasta llegar a 115148 hab. en 1938 (Weinberg, 1988, p. 260). En esas fechas el porcentaje de extranjeros, por su parte, ascendió de 30 a $45 \%$ para alcanzar su punto máximo hacia 1914 con $49 \%$ y descender nuevamente hasta $21 \%$ a mediados del siglo.

${ }^{12}$ Con la denominación de "Generación del 80" se reconoce en la historia argentina a la clase dirigente que acompañó el proceso de modernización que se produjo en el país a partir de las últimas dos décadas del siglo xIx y hasta el advenimiento del radicalismo a mediados de la década de 1910. Este grupo, a pesar de sostenerse en un régimen de democracia restringida, compartía su adhesión al positivismo y al liberalismo, confiando en que el progreso se alcanzaría mediante el libre juego de las fuerzas económicas, el respeto a las libertades individuales, y la europeización de la población y las costumbres. 
cos, estéticos y sociales. En efecto, a pesar de las dificultades que suponían la lejanía geográfica, la existencia de un mercado aún acotado y la dependencia respecto de los recursos tecnológicos y editores de la capital, en el periodo comprendido entre 1900 y 1930 se imprimieron más de un centenar de publicaciones. ${ }^{13}$ Bahía Blanca se convirtió, en función de ello, en un centro impresor ${ }^{14}$ de importancia dentro del territorio bonaerense, asumiendo una posición rectora en la zona sur de la provincia junto a Tandil, Tres Arroyos, Patagones y Olavarría y manteniendo una estrecha relación con el resto de los nodos emisores de la región.

Si las publicaciones periódicas se multiplicaron, no sucedió lo mismo con la edición de libros. Recién en 1912 se publicó la primera obra de factura local titulada La Senda de la Vida de Francisco Pablo de Salvo, a la que seguirían seis títulos aparecidos en los siguientes años (de la década de 1910), y dieciséis en el decenio siguiente (Paglialunga de Tuma, Bermejo Hurtado y Blanco de Anta, 1982, pp. 151-175). ${ }^{15}$ Estas cantidades, si bien demuestran un lento crecimiento, dan cuenta también de la imposibilidad de que los escritores hicieran de la literatura su medio de vida: la inserción en la burocracia estatal, en los ámbitos educativos, en el periodismo o en todos a la vez, se volvió para ellos una condición de subsistencia. Así lo confirmaba Arturo Igoillo Dantiacq (1928) cuando, luego de hacer un recuento del material editado en la ciudad desde 1900, afirmaba: "No pregunte el lector cual ha sido la acogida dispensada por el público a estos libros. En un ambiente metalizado como el nuestro, esas especulaciones del espíritu se cotizan poco o nada. Autores han habido que no han podido vender -jóigase bien!- diez libros. Y podemos afir-

${ }^{13}$ Para un estudio descriptivo de las revistas del periodo véase López Pascual y Agesta (2013, pp. 47-63).

${ }^{14}$ De acuerdo con Néstor Auza (2000, pp. 101-128), estos centros emisores surgieron en aquellas zonas donde confluían una serie de factores que contribuían a la producción, al consumo y a la circulación de estos medios como la concentración de autoridades políticas y administrativas, el incremento de la población urbana, la existencia de sectores ilustrados con elevados índices de alfabetización, la presencia de grupos vinculados a la vida cultural, y el desarrollo agrícola-ganadero asociado a la extensión de los medios de comunicación. Todas ellas se cumplían en la Bahía Blanca de principios de siglo. Sobre Bahía Blanca como centro emisor de la provincia y como nodo de irradiación regional, véase Agesta (2013b, pp. 67-93).

${ }^{15}$ Cabe destacar que varias de las obras registradas por las autoras formaron parte, en realidad, de colecciones de novelas semanales publicadas en la ciudad entre 1921 y 1923 . Arturo Igoillo Dantiacq (1928), en el número aniversario de la revista Arte y Trabajo remontó hasta 1902 el origen de la edición en Bahía Blanca. Su enumeración, sin embargo, incluía obras de carácter escolar, científico y jurídico, además de literario. 
mar, sin temor a ser desmentidos, que ninguno alcanzó a cubrir con la venta el importe de la edición”.

Mientras sus producciones poéticas y prosísticas eran publicadas eminentemente en las páginas de las revistas literarias o ilustradas, los libros, de existir, eran editados en imprentas porteñas que podían asumir los riesgos económicos de tales empresas. La inexistencia de un mercado editorial constituido para los autores locales ${ }^{16}$ fue entonces la causa de que aquellos que pretendieran vivir de la escritura se nuclearan en torno a la tarea periodística.

A pesar de que la literatura y el periodismo se presentaban como actividades cada vez más diferenciadas a nivel de las representaciones (Agesta, 2013a), no sucedía lo mismo cuando se trataba de defender los intereses laborales de los trabajadores intelectuales. Al igual que sucedía en Buenos Aires en torno a los grandes diarios (Rivera, 1998), la labor del periodista comenzó a profesionalizarse $y$, por ende, a organizarse nuevos espacios corporativos y de legitimación social que, como en el caso de los gremios de obreros gráficos, precedieron en muchos años a las asociaciones de escritores. ${ }^{17}$ La producción informativa fue adquiriendo un carácter industrial donde los diferentes engranajes del sistema editorial cumplían funciones cada vez más especializadas a cambio de un salario. La tarea de los periodistas comenzó a percibirse como un trabajo que requería de condiciones laborales dignas y de una remuneración adecuada. ${ }^{18}$

En concordancia con ello, durante las dos primeras décadas del siglo fueron habituales los artículos que los diarios, periódicos y revistas dedicaron a exaltar la misión de la prensa y a lamentar las condiciones de vida de los periodistas. Los bajos salarios, los problemas de salud provocados por el esfuerzo intelectual y, sobre todo, las urgencias a las que los sometía la lógica comercial de los medios, constituyeron tópicos frecuentes de la autorrepresentación discursiva que construyeron estos escritores desde antes de 1900. Habría que esperar hasta 1919 para que estas protestas genéricas y circunstanciales se articularan en incipientes demandas laborales que ese mismo año se concretarían en la primera agrupación de autodenominado carácter "gre-

${ }^{16}$ En efecto, como hemos explorado en otras ocasiones, existía en la ciudad un público lector que solicitaba y adquiría material bibliográfico de otras partes del país y del exterior. Probablemente, dicho mercado no era suficiente o no se hallaba interesado en las producciones locales. Agradezco a Juliana López Pascual por señalarme estos matices interpretativos.

${ }^{17}$ La primera asociación de escritores de la que tenemos noticias data de 1952.

${ }^{18}$ El Capitán Espingarda, “¡Oremus!”, Bahía Blanca, 11 de julio de 1909, p. 4. 
mial". Hasta entonces, la relativa escasez de trabajadores que vivían del ejercicio profesional de la escritura en la ciudad se sumó al principio paradójico de "desinterés" que atravesaba al proceso de conformación del campo intelectual en distintas latitudes para desalentar los intentos de nucleamiento profesional (Bourdieu, 1995). Aún durante la década de 1920 ambos obstáculos persistieron en el ambiente periodístico local confabulando contra la continuidad y el alcance efectivo de estas organizaciones. Las páginas de la prensa obrera, a pesar de su continua lucha por el reconocimiento de los derechos de los trabajadores, estuvieron igualmente permeadas por estas contradicciones. Así, en 1922 mientras el periódico socialista Nuevos Tiempos afirmaba su desconfianza frente a la "prostitución mental y moral" de la "plumas mercenarias" de los hombres "que utilizan como medio de vida la profesión periodística", ${ }^{19} \mathrm{El} \mathrm{Pro-}$ letario reclamaba por la falta de conciencia de clase del sector que le impedía unirse en pos de defender su estatuto profesional. ${ }^{20}$

Lo cierto es que, a pesar de estas acusaciones y pruritos, los periodistas bahienses habían ensayado ya por entonces varios proyectos de asociación bajo la figura del "círculo" que, sin embargo, fracasaron por su carácter interclasista, por la escasez numérica del sector y/o por la creencia en el valor simbólico de las actividades intelectuales que distinguían a los escritores de la prensa de sus pares obreros.

\section{LAS EXPERIENCIAS ASOCIATIVAS GREMIALES Y CORPORATIVAS}

\section{La primera asociación: del círculo al club social}

Contradiciendo el clásico libro de C. Galván Moreno (1944, p. 309), El periodismo argentino, que sitúa la primera asociación bahiense de esta índole en $1938,{ }^{21}$ hacia principios del siglo xx ya pueden encontrarse experiencias pio-

19 “¿El periodismo es la profesión de los fracasados?”, Nuevos Tiempos, 7 de octubre de 1922, p. 4.

20 "El gremio de periodistas", El Proletario, 10 de julio de 1922, p. 1.

${ }^{21}$ El autor se refiere al Círculo de la Prensa del Sur fundado el 19 de junio de ese año. Más allá de este estudio precursor, la bibliografía referida a la organización profesional de los periodistas en la Argentina se centra en el devenir de la Capital, identificando en gran medida los orígenes del movimiento gremial con el de las primeras iniciativas porteñas. Véase, por ejemplo, Miguel A. de Marco (2006) o Daniel Parcero (2010). Las referencias a las agrupaciones 
neras en este sentido que equiparan los procesos locales con los ocurridos en otras ciudades del país. En Buenos Aires, los intentos de organización de los trabajadores de la prensa habían comenzado unos años antes de 1890. En 1891 estas iniciativas se concretaron con la fundación del Círculo de Cronistas presidido por José Varas que un lustro más tarde se convertiría en el Círculo de Prensa. Los fines de la agrupación eran principalmente mutualistas y estaban orientados a proteger los intereses materiales, morales e intelectuales del gremio (Parcero, 2010). Con similares características se conformaron durante este periodo los círculos de Rosario (1894, 1900, 1910, 1920), de la Provincia de Buenos Aires (1908) y de los Territorios Nacionales (1917). En Bahía Blanca, las demandas corporativas se canalizaron tempranamente dado que en 1904 se creó la primera organización encargada de agrupar a los "obreros de la palabra" que, de acuerdo con el modelo porteño, recibió el nombre de Círculo de la Prensa de Bahía Blanca. A pesar de que sus funciones se orientaban principalmente a la defensa de la libertad de expresión, sus estatutos contemplaban cierta protección mutual que daba cuenta de la existencia de una incipiente identidad profesional.

La iniciativa surgió motivada por la visita de los periodistas italianos Salvatore Eracleto y Ettore Cauli quienes, en calidad de corresponsales viajeros de Il Corriere del Sud, Il Paese e Il Mattino, arribaron a la ciudad en el mes de marzo de 1904. Tal como informó oportunamente La Nueva Provincia, el propósito de ambos era conocer uno de los centros productivos y defensivos estratégicos de la Argentina a fin de completar los apuntes que integrarían su libro de próxima publicación América del Sud. Evolución social. Colegas de reconocida trayectoria en el ambiente local, como Enrique Julio, Juan Nicola (El Amigo Fritz), Salvador Dufaur y Antonio Infante, recibieron y homenajearon a los recién llegados organizando, entre otras cosas, una velada literario-musical benéfica que, más allá de la impresión que hubiere causado sobre Eracleto y Cauli -quienes partieron poco después-, resultó especialmente reveladora para los periodistas locales ya que, en palabras de El Comercio, "demostró la existencia de una fuerza útil y eficiente, de una energía hasta ese día desconocida ó desapercibida para muchos": "la del gremio de los que en Bahía Blanca, participan habitual ó accidentalmente de las tareas del periodismo". ${ }^{22}$ Esta

bahienses son asistemáticas y se encuentran casi exclusivamente en los listados de las delegaciones presentes en los congresos periodísticos nacionales o regionales.

22 "Acertado proyecto. Círculo de prensa", El Comercio, 26 de abril de 1904, p. 1. 
conciencia de unidad en torno al trabajo periodístico y a la existencia de una misión social, cultural y hasta económica compartida, fue el móvil inicial que culminó en la constitución del Círculo de la Prensa.

A pesar de lo enunciado en la hoja de Joaquín Perelló y en los mismos estatutos del Círculo, la nómina de sus fundadores ${ }^{23}$ y de la primera Comisión Directiva evidenciaban que la nueva entidad no incluía a todos los que participaban de "las tareas del periodismo", sino tan sólo a aquellos que conducían las empresas periodísticas, se desempeñaban como colaboradores habituales de la prensa local o actuaban como corresponsales de los grandes diarios de Buenos Aires. En efecto, para el ejercicio de 1904 la junta directiva estaba compuesta por Octavio Córdoba en calidad de presidente; el corresponsal de La Prensa, Aquiles San Romerio Bianchi, como vicepresidente; Gaspar A. Hortado como tesorero; Marcelino P. Garaña como periodista de El Comercio; en carácter de secretario-bibliotecario Enrique Julio, director de La Nueva Provincia, y como vocales: Eduardo Bambill, agente de La Nación, Luis J. Casterás en representación de El Diario, Joaquín Perelló, director de El Comercio, Andrés Cavallo del Diario del Comercio, Jesús C. Carrera de El País, Francisco C. Cordero y Urquiza de la Revista Comercial y Rodolfo Lazotti de la Patria degli Italiani. ${ }^{24} \mathrm{~A}$ diferencia de lo que iba a suceder en 1919, la mayoría de ellos -excepto Julio y Cordero y Urquiza-, si bien ejercían el periodismo, no se definían profesionalmente a partir de dicha práctica: Octavio Córdoba, por ejemplo, abogado de formación, se desempeñaba como director de la Escuela Superior de Comercio de la ciudad; San Romerio Bianchi había llegado a Bahía Blanca como miembro de las guardias nacionales e integraba a comienzos del siglo la Comandancia militar; Bambill era abogado; Hortado, escribano, y Perelló maestro, los tres eran docentes de la mencionada escuela. Lo cierto es que la comisión incluía en partes iguales a periodistas, profesionales y demás miembros de la minoría ilustrada bahiense. Antes que una delegación

${ }^{23}$ Entre los miembros fundadores se encontraba Aquiles San Romerio Bianchi, Marcelino P. Garaña, Gaspar A. Hortado, Enrique Julio, Antonio Infante, Eduardo Mata, Salvador Dufaur, Joaquín Perelló, Ricardo G. Ducós, Luis J. Casterás, Antonio S. Cartolano, Jesús C. Carrera, Octaviano Marambio Catán, Andrés Cavallo, Octavio Córdoba, Eduardo B. Bambill, Francisco Cordero y Urquiza, y Julio Salgado.

${ }^{24}$ Como podemos ver, el círculo reunía representantes de medios de Bahía Blanca (El Comercio, La Nueva Provincia y la Revista Comercial) y de Buenos Aires (La Nación, La Prensa, El Diario, Diario del Comercio, La Patria degli Italiani y El País). 
gremial, el Círculo representaba a los sectores letrados interesados en el desarrollo y la protección de la cultura escrita y de sus principales exponentes.

Difícilmente puede sostenerse, entonces, a partir de tal composición, el carácter interclasista que la agrupación preconizaba en su reglamento y que la presentaba como una asociación meramente profesional y de mutuo socorro. Sus objetivos de fomentar y sostener la unión y los intereses morales y materiales de quienes participaban en la actividad periodística, de aunar voluntades en el apoyo de iniciativas benéficas para la región, y de ejercer la protección mutua entre sus asociados parecían contradecir este carácter. Sobre todo si consideramos que se preveía la creación de una caja de socorros y subsidios para resguardar a sus miembros ante posibles arbitrariedades y se contemplaban mecanismos para asistir a los socios que se encontraran sin trabajo, asegurándoles así la continuidad en el desempeño profesional (Estatutos y reglamentos, 1904). No obstante, al comparar los estatutos con los de su análogo porteño, pueden descubrirse algunas diferencias que asimilaban la entidad bahiense a un círculo social de elite más que a una sociedad de índole gremial. En primer lugar, el organismo bonaerense excluía deliberadamente la instauración del sistema de pensiones que su par de Buenos Aires preveía en el artículo 10 del Estatuto. A cambio de la pensión vitalicia que el Círculo porteño ofrecía a los trabajadores inhabilitados para el trabajo y a sus viudas e hijos en caso de fallecimiento, la agrupación local instituía un subsidio temporario no mayor de tres pesos por día y una cuota única de 100 pesos para las respectivas situaciones. En segundo término, esta institución establecía mecanismos de admisión -el blackballing-que provenían de la tradición de los clubes sociales ingleses y que se practicaban ya en otras asociaciones exclusivas bahienses como el Club Argentino (Marcilese y Tedesco, 2006, pp. 29-30). Como señalan José Marcilese y Marcelo Tedesco a propósito de este último, el rechazo suponía un descrédito social que afectaba la reputación del candidato. A los criterios establecidos en el artículo 1-ser miembro del periodismo, poseer reconocida honorabilidad y ser presentado por dos integrantes del Círculo- se añadía, entonces, la aceptación de la Comisión Directiva en su totalidad. Este organismo consolidaba, de este modo, su posición interna dentro de la institución y, por extensión, dentro del medio periodístico local al reservarse el derecho de incluir y excluir a sus miembros según la voluntad de sus representantes más conspicuos.

El perfil aristocrático de la asociación bahiense se tornaba aún más evidente en la programación de sus actividades recreativas y culturales. La 
biblioteca constituía, por supuesto, un elemento fundamental en este sentido. En Buenos Aires como en Bahía Blanca, así como en la mayor parte de los círculos de sociabilidad modernos, la lectura de la prensa o de literatura constituyó un mecanismo de distinción sociocultural estrechamente asociado al desarrollo de estos espacios de reunión (Agulhon, 2009). Sin embargo, junto a la inauguración de la biblioteca y del centro de recreo, el Círculo de la Prensa bahiense proyectó la instalación de una sala de gimnasia y esgrima que, a cargo del profesor Carlos E. Gómez designado por la Comisión, se encontraba a disposición de los socios y de los no socios que contaran con el acuerdo previo de dicha junta. La esgrima constituía una práctica diferenciadora vinculada a la formación cultural y estética de los "caballeros honorables" que componían las clases altas en la Argentina (Gayol, 2008). La inauguración de un espacio destinado a este deporte en el Círculo de la Prensa evidenciaba, por lo tanto, la aspiración de refinamiento de sus integrantes y lo equiparaba a otros espacios reconocidos de la sociabilidad distinguida como el Jockey Club o el Club de Armas. ${ }^{25}$ Prueba de ello eran las notas que la prensa publicaba periódicamente dando cuenta de los adelantos del alumnado así como las exhibiciones de espada, sable o florete que el profesor y los estudiantes ponían en escena durante las funciones benéficas teatrales organizadas por la institución.

Así como el hábito de la lectura y la destreza en el manejo de las armas demostraban la distinción de los asociados, la independencia política del Círculo, enunciada de modo explícito en el reglamento, reproducía y reforzaba la escisión entre la alta sociabilidad y la política que caracterizaba a la modernización de la sociabilidad en las ciudades del país. ${ }^{26} \mathrm{El}$ inmediato ofrecimiento de la presidencia honoraria a conservadores de distintas banderías como Bartolomé Mitre, Estanislao Zeballos, José Posse, ${ }^{27}$ aun cuando algunos de

${ }^{25}$ El éxito de la esgrima y la importancia social que se le asignaba en la formación del carácter de los jóvenes caballeros fue explícitamente enunciado por La Nueva Provincia a propósito de la iniciativa del Círculo. "Círculo de Prensa. Sala de Esgrima", La Nueva Provincia, 30 de septiembre de 1904, p. 1.

${ }_{26}$ "El Círculo de Prensa, es ageno á todo debate político ó religioso. Cualquier acto ó manifestación de tal naturaleza, es nulo o de ningún valor y no puede comprometer a la institución” (Estatutos y reglamentos, 1904, p. 13).

${ }^{27}$ Marcela Vignoli (2015, p. 30) señala que esta voluntad de vincularse con figuras reconocidas del poder político nacional era frecuente entre las asociaciones de fines del siglo xIx y principios del xx. La autora sostiene que, de este modo, estas entidades establecían un diálogo fluido con las instancias de poder, sabiendo que su supervivencia dependía en gran medida de la obtención de recursos y de reconocimiento para sus fines. 
sus miembros más conspicuos -como Enrique Julio- eran reconocidos militantes radicales, pretendía demostrar que los fines culturales y solidarios de la agrupación se hallaban por encima de las luchas partidarias. Leandro Losada (2006, pp. 547-572) sostiene, en este sentido, que la construcción de una clase distinguida y "civilizada" en Buenos Aires entre 1880 y 1916 requirió del desplazamiento de la política como factor convocante de la vida social. Los enfrentamientos partidarios y las tensiones políticas fueron relegadas de la sociabilidad a fin de reforzar la cohesión de la elite y consolidar el proceso civilizatorio a la par que la política se profesionalizaba y se diversificaba la pertenencia social de sus protagonistas. Esta convivencia entre principios modernos y pautas sociales tradicionales situaba al Círculo en una posición intermedia entre la asociación profesional y el club social, dando cuenta, entonces, de los rasgos particulares que adquiría el proceso de modernización del campo periodístico en Bahía Blanca. Efectivamente, así como el número de socios impedía sostener un sistema de pensiones y un grupo de notables se reservaba el derecho de admisión y la toma de decisiones dentro de la entidad, el carácter incipiente de la profesionalización dificultaba la identificación de sus potenciales integrantes. Antes que reunir a todos los que formaban parte del oficio, el Círculo cumplía una función configuradora del mismo en tanto desde el Estatuto se establecía que se consideraba "miembro del periodismo" a quien hubiera ejercido la profesión por lo menos un año o se encontrara ejerciéndola en el momento, fuera colaborador habitual en los diarios locales, con declaración expresa de sus respectivas redacciones, desempeñara el cargo de corresponsal efectivo de los principales diarios de la capital federal o ejerciera como publicista (Estatutos y reglamentos, 1904, p. 6).

El hecho de que decidieran añadir estas aclaraciones a un reglamento que había sido en su mayor parte copiado del Círculo porteño, revelaba que los fundadores del organismo local percibían cierta indeterminación en la definición de los "trabajadores de prensa" que consideraban necesario esclarecer. La pertenencia quedaba reducida, de este modo, al ejercicio de la escritura o a la vinculación con el mundo empresarial del periodismo; los obreros gráficos y los demás agentes del proceso productivo eran exceptuados de la membresía y conformaron sus propias asociaciones profesionales, muchas veces en franco conflicto con los patrones que nucleaba el Círculo.

La condición elitista de la institución era percibida también por sus contemporáneos y fue, en gran medida, la causa de su disolución. Su función de defensa del periodismo quedó desplazada en favor de las actividades 
sociales y de la agenda política y cultural del momento. La labor del Círculo se reducía, de hecho, a la organización de fiestas y espectáculos teatrales y al patrocinio de causas, como la creación del Colegio Nacional en 1906 (González Coll et al., 1981) y de los Tribunales Costa Sud en 1905, que involucraban a sus miembros aunque poco tuvieran que ver con los intereses periodísticos específicos. Únicamente ante la detención del vicepresidente de la institución y corresponsal de La Prensa Aquiles San Romerio Bianchi por parte del comisario Hilario R. Soiza durante una función en el Teatro Politeama, el organismo decidió accionar denunciando ante las autoridades provinciales y el Círculo de la Prensa de Buenos Aires el acontecimiento que había provocado "dolorosa indignación en el seno de nuestra sociabilidad" y destacando la "actitud moderada y caballeresca" del afectado.$^{28}$ Dado que en ningún momento, ni en las cartas ni en la prensa, se especificaron las causas que habían motivado el arresto, y considerando que San Romerio Bianchi se desempeñaba como corresponsal de un periódico porteño pero no dirigía ya ningún medio de prensa local, podemos suponer que el conflicto se desencadenó por motivos personales $o$, inclusive, políticos ${ }^{29}$ que no afectaban directamente el derecho de libertad de prensa. Por otra parte, los términos en que se formularon las notas remitían más a una reivindicación del honor frente a la ofensa social que a valores propiamente periodísticos y modernos como la libre expresión.

Finalmente, en 1908 un nuevo incidente puso en evidencia la naturaleza de la institución precipitando su disolución. En efecto, la actitud asumida por el Círculo en apoyo del juez Bambill contra Adam Giménez, director del periódico socialista Hoja del Pueblo, generó la oposición de parte del periodismo local. Así lo expresó Hoja del Pueblo cuya opinión, aunque condicionada por su participación en la situación, condensaba la de muchos de sus colegas:

${ }^{28}$ El episodio quedó registrado en la prensa local y también en la memoria del Círculo porteño el cual, a pesar de manifestar su pesar, evitó pronunciarse ante lo ocurrido alegando que en ningún momento se le informaban de las causas y los pormenores de la detención. "Círculo de la Prensa. Publicación oficial”, La Nueva Provincia, 5 de noviembre de 1904, p. 1; Círculo de la Prensa. Memoria de los Trabajos realizados durante el ejercicio de 1904-1905, 1905, pp. 30-33.

${ }^{29}$ Podemos conjeturar que existía una rivalidad política en tanto Aquiles San Romerio Bianchi había sido el fundador de El Deber, diario radical, mientras el comisario era un representante del gobierno conservador provincial, responsable de su nombramiento. 
El Círculo de la Prensa, fundado hace algunos años por periodistas de valer, fue creado á los fines de prestar solidaridad á los del gremio.

El alto espíritu solidario desarrollado poderosamente en otras épocas á ido poco á poco, desapareciendo hasta el punto de verse aquella grandiosa institución reducida á un vulgar centro recreativo. [...]

El círculo, con su actitud, pone á los periodistas de la república en la picota, amordaza á la prensa y da margen para que cualquier funcionario atacado lleve ante la justicia á periodistas, más aún, silencia una enormidad judicial pronta á repetirse. [...] En síntesis. El círculo permite que se fusile á un inocente para luego protestarla. Bien, muy bien piensan algunos periodistas bonaerenses ¿verdad? ${ }^{30}$

El episodio suscitó el enfrentamiento entre los medios de la localidad en tanto un grupo de periodistas bahienses decidió dirigirse al Círculo porteño para informarle sobre lo ocurrido y solicitar su intervención en el conflicto. ${ }^{31}$ La Revista Comercial -dirigida por Ricardo Ducós- manifestó entonces su disconformidad respecto de esta apelación diciendo que "la solidaridad [entre los miembros del periodismo] no obliga á una intervención continua que llegue á abarcar todos los casos, porque si así fuera importaría un tutelaje imposible para la existencia individual". ${ }^{32}$ Ducós, ligado al gobierno comunal del Comité Popular, ${ }^{33}$ no dudó en apoyar el accionar del juez Bambill y del comisario Félix Lavié, responsable de la denuncia de injurias que había originado el proceso contra Giménez. Hoja del Pueblo, por el contrario, se fundó en

30 "Círculo de la Prensa. Faltando a su principio. Negando su intervención”, Hoja del Pueblo, 24 de junio de 1908, p. 1. Cursivas mías.

${ }^{31}$ De acuerdo con las memorias del Círculo de la Prensa de Buenos Aires, era frecuente que los círculos del interior recurrieran al de la capital para que mediara en cuestiones relativas a la defensa de los periodistas y de la libertad de prensa. La intervención, en estos casos, consistía en la manifestación explícita de la solidaridad gremial. Cabe señalar que en los estatutos del Círculo porteño de 1902 no se definía claramente su alcance territorial, aunque es posible vislumbrar a través de las disposiciones generales que su tutela podía extenderse sobre todo el país: "La Comisión Directiva podrá promover la fundación de asociaciones dependientes de esta, en otras ciudades de la República y las relaciones entre ellas y la Central, serán regidas por un reglamento que dictará la misma Comisión” (Estatutos y reglamentos, 1902, pp. 22-23).

32 ¿Por qué disentimos? Revista Comercial, 16 de mayo de 1908, p. 14.

33 El Comité Popular era una agrupación local formada con fines electorales que nucleaba miembros de distintos orígenes partidarios. Bajo esta denominación, los radicales bahienses pudieron sortear la política de abstencionismo de la UCR y, en alianza con algunos conservadores, acceder al gobierno comunal (Laurent, 1997). 
su origen socialista para, sustentado en los principios de libertad de prensa y solidaridad gremial, encabezar el reclamo en favor de su director.

\section{El ensayo "gremial"}

Más allá de los intereses particulares, lo cierto es que este incidente catalizó la disconformidad de parte de los trabajadores del periodismo para con la entidad. En efecto, entre 1908 y 1919 no encontramos ninguna otra mención al Círculo ni en la prensa ni en las guías comerciales, lo cual nos permite conjeturar que, luego de lo sucedido, el desprestigio de la entidad y su falta de representatividad llevó a su definitiva desaparición. En 1919, sin embargo, un segundo intento de institucionalización tuvo lugar cuando el personal de redacción de los diarios locales reunido en la sede del periódico de los empleados de comercio, Evolución, decidió organizar "una sociedad de periodistas, tendentes a velar por los intereses del gremio y, a dignificar la profesión" ${ }^{34}$ Ricardo Redondo como presidente, Pedro Pitiot Álvarez como secretario. Eladio Andino Ortiz y Oscar Fuentes Urios conformaron entonces una comisión provisoria encargada de convocar una asamblea y constituir definitivamente la asociación mediante la redacción de sus estatutos. Todos ellos, a diferencia de los que habían actuado en 1904, se definían eminentemente como periodistas y, al menos en el caso de Pitiot y Fuentes Urios, contaban con experiencias gremiales previas en su España natal vinculadas a la militancia en las filas republicanas. ${ }^{35}$ Así, convocado por estos hombres, el 8 de junio de 1919, en la Secretaría de la Liga del Sud, se creó el Círculo de Periodistas de Bahía Blanca con la asistencia de los miembros de la mencionada comisión a los que se sumaron Alberto Pidemunt, José Cimadamore, Francisco Loge,

34 “Reunión de periodistas", Bahía Blanca, 6 de mayo de 1919, p. 4.

${ }_{35}$ Pedro Pitiot Álvarez (Gijón, 1878-Buenos Aires, 1937), por su parte, se dedicó al ejercicio del periodismo y a la militancia en el Partido Republicano Federal desde su juventud en España. Allí dirigió varios periódicos y en 1909 participó en la constitución de la Asociación de Prensa de Gijón. Debido a sus conflictos con los sectores monárquicos, fue condenado al destierro y se instaló en Bahía Blanca entre 1911 y 1912. Oscar Fuentes Urios (Alicante, 1891-Bahía Blanca, 1946) fue docente, periodista y escritor. Llegó a la ciudad en 1918 y, como liberal y demócrata, combinó el magisterio con las tareas de periodista. Formó parte de las redacciones de El Atlántico, La Nueva Provincia y El Censor y publicó ensayos educativos y relatos (Freinkel, 1993, p. 46; Libro Genealógico, 2011; Heredero Clar y Abad Martínez, 1928). 
Manuel Cobián, Samuel Morales y José Posso Ardizzi. ${ }^{36}$ Si bien el término "círculo" parecía seguir remitiendo a una entidad de perfil eminentemente social, ciertas modificaciones enfatizaban su carácter gremial distanciándolo de su antecesor. Ya no se hablaba de "la prensa" en un sentido genérico que acentuaba su misión moral y cultural en la sociedad; por el contrario, su nombre aludía a los trabajadores mismos, a los "periodistas" cuyos derechos pretendían defender. La utilización de otros términos como "clase" y "gremio", ausentes en el reglamento del Círculo de la Prensa de 1904, denotaban la creciente conciencia corporativa. Aunque, al igual que antes, los estatutos proclamaban la independencia política y religiosa, la definición de los asociados y las principales finalidades de la agrupación se diferenciaban sustancialmente de las anteriores:

Artículo 1- Bajo la denominación: "Círculo de Periodistas de Bahía Blanca", queda constituida en esta ciudad una entidad, cuyos propósitos se especifican en los subsiguientes apartes:

a) Procurar las más francas relaciones entre aquellos que ejercen el periodismo como profesión y los empleados de las administraciones de los diarios.

b) Propender al mejoramiento moral y material de la clase.

c) Velar por la moralidad del gremio.

d) Establecer la ayuda mutua para lo cual se arbitrarán recursos de la forma que la comisión directiva crea conveniente. En caso de enfermedad de un asociado (a excepción de las llamadas secretas), se le facilitará asistencia médica y medicamentos y si falleciese, se abonarán los gastos de sepelio. Además, se le entregará a la viuda una asamblea general, al año de constituida la sociedad, en cuya fecha empezará a regir la ayuda mutua. Si el fallecido no dejara viuda, pero si padres e hijos de corta edad, que careciesen unos y otros de medios para su sostenimiento, les será entregado el socorro.

\section{Los socios}

Art. $2^{\circ}$ - Habrá tres clases de socios; efectivos, honorarios y protectores. Podrán ser socios efectivos todos los periodistas en activo y los que temporariamente dejen de

${ }^{36}$ Libro de Actas del Círculo de Periodistas de Bahía Blanca, 8 de junio de 1919, f. 2. Archivo Familiar Pitiot, Bahía Blanca. Agradezco a Juan Carlos Pitiot por haberme permitido acceder a este documento. 
estarlo, quedando al criterio de la asamblea la clasificación de estos últimos; los segundos aquellos que por su cultura y merecimientos, sean designados en reunión general y los terceros los que quieran contribuir al sostenimiento de la sociedad.

Art. 3- No podrán pertenecer en carácter de socios activos, al "Círculo de Periodistas de Bahía Blanca", los directores de diario, que a la vez sean propietarios o copropietarios del mismo. ${ }^{37}$

Como se indica en el artículo 2, para pertenecer al círculo se requería de cierta continuidad en la profesión ya que sólo se contemplaba una suspensión temporaria de la actividad. De esta manera, el reglamento resultaba mucho más restrictivo que el de 1904, donde únicamente se exigía haber ejercido el periodismo durante un año y se incluían otras figuras como los corresponsales y los publicistas. La existencia de un grupo reconocible y relativamente estable de "trabajadores de la pluma", ya en franco proceso de profesionalización, posibilitaba el surgimiento de esta entidad y el sostenimiento de un sistema de ayuda mutua (art. 1, inc. d). Por otra parte, la asociación adquiría cierto carácter clasista al excluir explícitamente a los propietarios de los diarios y al enunciar entre sus objetivos la lucha por las condiciones materiales de sus miembros. Este perfil, ausente en los proyectos anteriores -incluso posteriores-, hasta la formación de la filial local del Sindicato Argentino de Prensa, suponía reconocer a los periodistas como obreros insertos en empresas comerciales. La agrupación recibió primeramente el apoyo de varios periodistas locales entre los que se encontraron, además de los antes mencionados, Ismael López Camelo, Domingo Solano, José Franzetti, Francisco Pablo de Salvo y Blas Fanelli.

La propuesta no se presentaba de manera aislada sino que lo hacía en consonancia con otros puntos del país. Como señala James Cane (2007, pp. 32-33), ese mismo año en Buenos Aires Octavio Palazzolo y José Gabriel de La Prensa intentaron infructuosamente formar un sindicato de periodistas cuestionando las nociones románticas del periodismo vigentes hasta entonces. ${ }^{38}$ En efecto, el ejemplo porteño había sido destacado por la prensa bahiense

${ }^{37}$ Libro de Actas del Círculo de Periodistas de Bahía Blanca, 8 de junio de 1919, fs. 3-5. Archivo Familiar Pitiot, Bahía Blanca. Cursivas mías.

${ }^{38}$ De acuerdo con la hipótesis de Cane, durante la década de los veinte estos conflictos se produjeron como consecuencia de un triple desencuentro: entre las concepciones normativas del periodismo, la jurisprudencia al respecto y el funcionamiento de la industria periodística. 
que, a pesar de reconocer las limitaciones a las que se hallaba sometido el sector en el interior del país, consideraba necesario la formación en la ciudad de instituciones análogas autónomas o dependientes de la central que fortalecieran la solidaridad profesional y garantizaran el futuro de los trabajadores: "El ejemplo de los periodistas porteños debiera ser imitado en el resto del país. [...] En Bahía Blanca, como en muchas otras ciudades del país, si el exiguo número de periodistas no permite formar entidades autónomas, se puede por lo menos formar secciones dependientes de la Asociación que se cree en la capital, adhiriéndose como allí a los gráficos locales." ${ }^{39}$

Tal como había previsto El Censor y al igual que en la capital, aunque de manera menos conflictiva, en Bahía Blanca la tentativa no prosperó ya que, a pesar de su aparente éxito inicial, la falta de apoyo de la sociedad local, el reducido número ${ }^{40}$ y el escaso compromiso de algunos de sus integrantes implicaron, finalmente, su desaparición. A medida que se suceden las páginas de libro de actas se percibe una disminución de la asistencia de la misma Comisión directiva a las reuniones acordadas: de los cinco miembros originales, cuatro asistieron al encuentro del 27 de junio, dos al del 4 de agosto y tres al del 18 de octubre. Para entonces, Ricardo Redondo había manifestado su voluntad de retirarse del Círculo y del periodismo y Pidemunt, el tesorero, había trasladado su residencia a Coronel Pringles, debiendo también abandonar su cargo. Si bien los integrantes restantes decidieron convocar para la presidencia al reconocido periodista y docente Julio García Hugony y flexibilizar las condiciones de admisión a fin de aceptar como socios a los colegas que no estuvieran en activo y a los corresponsales de los diarios de Buenos Aires, la ausencia de un interés genuino por contar con una organización de este tipo en Bahía Blanca terminó con su existencia. ${ }^{41}$ La breve vida del Círculo daba cuenta de algunos de los obstáculos que encontró el periodismo bahiense en

\footnotetext{
39 “El gremio de periodistas. Un buen ejemplo", El Censor, 20 de marzo de 1919, p. 4. Cursivas mías.

${ }^{40}$ Si bien carecemos de información estadística al respecto, la exploración de la prensa local permite afirmar que el número de periodistas creció de manera mucho más limitada que el de las publicaciones. Tal como hemos analizado en otras ocasiones (Agesta, 2016), era un grupo reducido de personas la que escribía en los distintos medios de comunicación e, incluso, llevaba adelante varios proyectos editoriales.

${ }^{41}$ Libro de Actas del Círculo de Periodistas de Bahía Blanca, 20 de octubre de 1919, f. 11. Archivo Familiar Pitiot, Bahía Blanca.
} 
su proceso de agremiación: la excesiva movilidad espacial de los agentes culturales que conspiraba contra la continuidad de los proyectos y la escasez de periodistas profesionales que, sin ser empresarios de la prensa, pudieran asumir la defensa de sus derechos.

\section{La vuelta al Círculo bajo la tutela platense}

En 1904 el Círculo había tomado como modelo y referencia a su par porteño cuyo reconocimiento oficial de parte del Círculo de Buenos Aires se había apresurado a solicitar (art. 32, inc. p) y había establecido de inmediato vínculos con figuras del periodismo de alcance nacional como Bartolomé Mitre, José Posse y Estanislao Zeballos, invitándolos a integrarse a la entidad en calidad de miembros honorarios. Inclusive, ante circunstancias conflictivas era al Círculo de Buenos Aires al que se recurría en busca de mediación o de legitimación de una de las partes. ${ }^{42}$ En 1919 fue igualmente el nuevo sindicato capitalino el ejemplo recogido por los periodistas locales. Hacia 1921, sin embargo, esta situación varió como consecuencia de la conformación del Círculo de Periodistas de la Provincia de Buenos Aires, en 1908, cuya jurisdicción se extendía sobre la ciudad. La Plata, antigua rival de Bahía Blanca, adquiría entonces injerencia directa sobre los asuntos locales. ${ }^{43}$

Fue así como, en 1921, frente a un incidente que enfrentó a la policía bahiense con el diario El Atlántico, los periodistas locales se dirigieron a la institución de La Plata solicitando su intervención mediante el envío de una comisión formada por los señores Rodolfo César, Rodolfo Almada y Ubaldo López Cristóbal, en defensa de la libertad de expresión. Una vez cumplida su tarea, los delegados platenses propusieron a sus colegas locales la creación de una filial del Círculo de Periodistas. La idea encontró una buena acogida por parte de los intelectuales bahienses que inmediatamente se reunieron en

${ }^{42}$ Círculo de la Prensa. Memoria de los trabajos realizados durante el ejercicio de 1904-1905. Buenos Aires, 1905, pp. 30-33.

${ }^{43}$ La rivalidad entre Bahía Blanca y La Plata se remontaba a las últimas décadas del siglo XIX cuando, frente a las aspiraciones de la primera de convertirse en capital de la provincia de Buenos Aires, se decidió la fundación de la segunda como centro político-administrativo próximo a la capital. Durante las primeras décadas del nuevo siglo, el encono hacia los "pantanos de Tolosa" continuaría vigente a partir de las críticas que los medios bahienses realizarían con frecuencia a la política platense, su subordinación a Buenos Aires, su descuido de las localidades bonaerenses y sus excesivos gastos administrativos (Ribas, 2008). 
la Biblioteca Bernardino Rivadavia para constituir una comisión directiva y redactar los estatutos correspondientes. En palabras del diario El Siglo, se dieron cita en la biblioteca "todos los directores de diarios y la mayor parte de los redactores y réporters, como así mismo varios caballeros que hacen periodismo de vacaciones" ${ }^{44}$ La composición de la asistencia revelaba, por un lado, la heterogeneidad del mundo periodístico de la época que reunía a profesionales y aficionados de la escritura y, por el otro, la naturaleza más ecléctica de la organización respecto de su predecesora. A diferencia de ella, los directores de los medios participaron en su totalidad de la nueva institución tal como quedó evidenciado ya en la comisión designada para estudiar los estatutos en la que se encontraban Enrique Julio de La Nueva Provincia, Edmundo Calcagno de El Atlántico, Eusebio Heredero Clar de El Orden, Federico Wortelboer de El Censor, Antonio Infante de El Siglo, Carlos Verzura en representación de los corresponsales y Rogelio Estévez Cambra como colaborador no enrolado administrativamente en las redacciones. Si bien una vez que los periodistas platenses hubieron partido no se encuentran muchas menciones a la filial local-excepto en las coyunturas que involucraban a sus miembros-, consideramos que su importancia radicó fundamentalmente en la dimensión regional del proyecto que pretendía unificar al periodismo de la provincia de Buenos Aires bajo la dirección de la asociación platense. De esta manera, y a pesar de los reclamos contra el gobierno provincial por el descuido en que tenía a la "Liverpool Argentina", como se denominaba a Bahía Blanca, los periodistas locales se reconocían como parte subordinada, aunque imprescindible de la central capitalina.

Un último intento de nucleamiento bajo la figura del Círculo se realizó, como indica Galván Moreno, en 1938 y recibió por nombre el de Círculo de la Prensa del Sur (Marcilese, 2013, pp. 191-223). Como lo sugería su denominación, una de las principales diferencias que lo distinguían de sus predecesores era su extensión territorial, dado que pretendía reunir en una única entidad la representación de los periodistas de la jurisdicción de los tribunales de Costa Sur, Territorios Nacionales, Pampa Central, Río Negro, Neuquén, Chubut, Santa Cruz y Tierra del Fuego. Como en los casos anteriores -excepto en 1919- su carácter era fundamentalmente ecléctico y su masa societaria se componía tanto de propietarios y personal jerárquico como de periodistas y empleados de la prensa. No obstante ello, José Marcilese señala que hacia

44 “Círculo de Periodistas", El Siglo, 8 de marzo de 1921, p. 6. 
mediados de la década de los cuarenta y en consonancia con el Estatuto del Periodista aprobado en 1944 (decreto-ley 7618/46) y la Ley 12.908 que lo ratificó en 1946, dicha composición se fue inclinando paulatinamente en favor de los trabajadores y la institución adquirió así un perfil sindical más marcado que se acentuaría en los años posteriores. Finalmente, y como consecuencia de sus transformaciones, la organización se desarticuló y parte de sus asociados se incorporaron al Sindicato de Prensa del Sur fundado en 1951 como filial local del Sindicato Argentino de Prensa (López Pascual, 2012).

Si bien es cierto que las experiencias de los años treinta y cuarenta escapan a nuestro marco temporal, resulta interesante destacar que habría que esperar aún varias décadas para que se conformaran asociaciones profesionales duraderas que representaran a los trabajadores del periodismo y sus intereses gremiales. En los primeros 30 años del siglo xx en Bahía Blanca, al igual que en otros lugares del país, la proliferación de medios periodísticos y la relativa autonomización de la escritura impulsaron la constitución de agrupaciones profesionales que congregaran y protegieran a los periodistas. Ahora bien, ¿cómo explicar el sucesivo fracaso de todas ellas? Ciudades de desarrollo acelerado como la que nos ocupa sufrieron también procesos análogos. Vale citar al respecto el caso de Rosario donde, hasta su definitiva conformación en 1920, varios círculos de la prensa surgieron para desaparecer inmediatamente.

Podemos aventurar que el rápido crecimiento económico, demográfico y cultural de la localidad suponía también una modernización de las formas asociativas y de organización. Siguiendo el modelo de las grandes urbes, los periodistas bahienses se agruparon entonces en sociedades profesionales que les otorgaban identidad y visibilidad institucional legitimando su existencia y su intervención corporativa en los asuntos locales. Esta voluntad asociativa se fundaba, asimismo, sobre la propia experiencia profesional y política que muchos de estos periodistas traían de sus naciones de origen. Sin embargo, la autonomización de la escritura en Bahía Blanca era aun sumamente incompleta y operaba más a nivel de las representaciones que de las prácticas: muy pocos periodistas o escritores hacían de esta su actividad principal. Excepto para los propietarios de las empresas periodísticas más importantes, la colaboración en los medios de prensa era una tarea complementaria de sus ocupaciones rentadas. De esta manera, se producía una tensión entre cierta concepción aristocrática de la escritura y una industria gráfica en plena modernización tecnológica y económica. 


\section{INTERVENCIONES, OPINIONES Y OMISIONES}

Además de evidenciarse en las dificultades que experimentaron las asociaciones bahienses de periodistas, estas contradicciones atravesaron también los debates en torno a la profesión y a la misión de la prensa. El diferente peso relativo que dichos temas tuvieron en las hojas periódicas dio cuenta de una agenda desigual de preocupaciones que priorizaba problemáticas de orden general y principista frente a otras de carácter gremial o laboral. En este sentido, resulta interesante recuperar la recepción que tuvieron en la localidad acontecimientos como la organización del primer Congreso de la Prensa Argentina, realizado en Buenos Aires en 1901, y los proyectos legislativos relativos a la propiedad intelectual, la jubilación de los periodistas y su estatuto profesional frente a la amplia cobertura brindada a otro tipo de problemáticas asociadas a la violación de la libertad de imprenta.

El Primer Congreso de la Prensa Argentina se realizó por iniciativa del Círculo de la Prensa porteño y tuvo como asunto principal, a decir de Juan Rómulo Fernández (1943), la misión del periodismo. El programa, redactado por la Comisión directiva del Círculo y publicado en los diarios bahienses, no se limitaba, sin embargo, a cuestiones morales y abstractas sino que incluía igualmente tópicos referidos a las relaciones del periodista con las autoridades, instituciones y "cuerpos morales", los vínculos entre las empresas de diarios y los periodistas, la propiedad literaria, las instituciones protectoras y cooperativas entre periodistas, las tarifas de transporte, correos y telégrafos junto con otros centrados en la definición de la profesión y el trabajo de mujeres y niños en el sector. ${ }^{45}$ Aun así, y a pesar de que el evento se organizó en tres secciones dedicadas respectivamente a "Cuestiones morales y legislativas", "Cuestiones económicas y sociales" y "Cuestiones profesionales", 46 López Cepeda no dudó en afirmar, con motivo de la realización del congreso de periodistas de 1938, que se había tratado de

una expresión de las patronales periodísticas de la época en la que se estudiaron cosas relativas a las mismas, generalidades sobre prácticas y ética de la

${ }_{45}$ Puede consultarse el programa completo del Congreso en "Congreso periodístico argentino", La Nueva Provincia, 19 de marzo de 1901, p. 1; o "El Congreso periodístico", El Heraldo, 23 de mayo de 1901, p. 1.

${ }^{46} 1^{\circ}$ Congreso de la Prensa Argentina (1901). 
prensa, aspiraciones inconcretas, para resultar puramente accidentales y sin mayor fortuna los problemas de genuino interés gremial, algunos de los cuales, al ser insinuados, produjeron verdadero revuelo y llegaron a concretarse muy atenuadamente. ${ }^{47}$ (Gaceta de la Federación Argentina de Prensa, 1970, p. 12, citada en Parcero, 2010, p. 24).

Más allá de las razones coyunturales que le dieron origen, esta interpretación parece reafirmarse a partir de la confrontación con las fuentes locales. Los diarios La Nueva Provincia y El Porteño -los más destacados en el ámbito bahiense- decidieron responder a la convocatoria de la Comisión Directiva y hacer acto de presencia en el Congreso mediante la designación de delegados escogidos de entre los miembros de la prensa y del círculo de Buenos Aires. ${ }^{48}$ Tanto la hoja de Enrique Julio como El Heraldo de Adam Giménez y en menor medida El Porteño de Mariano Reynal, brindaron una vasta cobertura al acontecimiento, enfatizando, en todos los casos, el tratamiento de cuestiones referidas a la libertad de expresión, la moralidad de la noticia y la confraternidad entre periodistas que contribuían a consolidar "el orden y la civilización" nacionales. ${ }^{49}$ A pesar de esta coincidencia, algunos matices diferenciaron el discurso de los tres periódicos. Así, La Nueva Provincia, responsable de introducir los principios de la prensa moderna e independiente en la ciudad (Llull, 2005), recalcó la dimensión ética del periodismo -"el más grave problema del diarismo contemporáneo"- al transcribir de forma completa -en ediciones sucesivas- el libro de Alejandro Ghigliani La moralidad de la noticia, presentado en el marco del Congreso, pero también, y sobre todo, se preocupó por dejar en claro su lugar en el concierto de la prensa argentina como representante del sur del país. ${ }^{50}$ El Heraldo, por su parte, rescató de los

${ }^{47}$ Gaceta de la Federación Argentina de Prensa, 1970, p. 12, citada en Parcero (2010, p. 24).

${ }^{48}$ La Nueva Provincia designó a Manuel María Oliver, integrante de la redacción del diario metropolitano El Tiempo para representarla, mientras que El Porteño tuvo como vocero a Fernando Maldonado, prosecretario de la Comisión Directiva del Círculo porteño y secretario de la Comisión Organizadora del Congreso. "Primer Congreso de la prensa argentina. Su clausura”, La Nueva Provincia, 1 de junio de 1901, p. 1, y $1^{\circ}$ Congreso de la prensa argentina (1901).

49 "El Congreso Periodístico", La Nueva Provincia, 29 de mayo de 1901, p. 1.

${ }^{50}$ Entre fines de mayo y principios de junio, el diario reiteró afirmaciones como las que siguen: "LA NUEVA PROvinCIA ha designado sus delegados después de haberse inscripto como uno de los primeros adherentes y hoy cumple el grato deber de enviar su saludos á los señores Delegados", "LA NUEVAPRovincia no faltó a la hora de la cita", "Después de este primer llamado á que acudimos presurosos, esperamos desde nuestro modesto puesto en el grueso del ejército del periodismo, el triunfo definitivo de sus elevados propósitos". También reprodujo el 
debates aquellas problemáticas relativas a la práctica del periodismo en las provincias y a la restricción de la libertad de imprenta que lo atañían especialmente, ya que durante el mes de junio, ofendido por las críticas vertidas en las páginas del periódico, el comisario Ibarra había encarcelado a su director Adam Giménez sin siquiera someterlo a un proceso judicial. El Porteño, finalmente, se limitó a señalar resoluciones puntuales como la de supresión de los avisos de duelos y suicidios en los diarios y la creación de una escuela de periodistas. En ningún caso las cuestiones laborales enunciadas en el temario ocuparon la atención de los medios bahienses. Las dificultades a las que se veían sometidos ellos mismos como consecuencia de la censura -la persecución policial y las presiones de las facciones políticas- orientaron la selección de los asuntos a comentar al igual que la inexistencia de un cuerpo de periodistas profesionales ${ }^{51}$ de relevancia socavó el interés por tales tópicos. La realización del Congreso era, por lo tanto, valorada como instancia de reflexión y de unión de quienes se consideraban abanderados del progreso y, en este sentido, las publicaciones bahienses procuraron hallarse representadas, aunque más no fuera por delegados no locales.

En este marco, y no obstante el tiempo transcurrido, es que puede comprenderse la escasa atención que prestaron los impresos a los diversos proyectos de ley dirigidos a proteger los derechos intelectuales y laborales de los periodistas que fueron presentados ante la Cámara de Diputados de la nación durante las décadas de 1910 y 1920. La necesidad de un sistema jurídico de defensa de la propiedad intelectual en la Argentina se manifestó desde comienzos del siglo xx y se concretó luego de la visita de Georges Clemenceau, en 1910, con la sanción de la Ley 7092 y sus posteriores ampliaciones y modificaciones. Hasta entonces los conflictos vinculados a la autoría se habían resuelto mediante la apelación al Código Civil y del artículo 17 de la Constitución nacional. La nueva legislación, si bien establecía la facultad del autor de disponer de su obra y de iniciar acciones civiles por daños y perjuicios a quienes la reprodujeran sin su consentimiento (Ley 7092, 1910, art. 3 y 9), no preveía sanciones penales para sus potenciales violaciones, razón por la cual

intercambio de telegramas que su redacción mantuvo con el presidente del congreso, Estanislao Zeballos, quien, por su parte, se hallaba en contacto con Bahía Blanca a partir de sus viajes por la Patagonia. Véase Cernadas (1994).

${ }^{51}$ Vale la pena recordar, como señalamos más arriba, que el primer círculo local fue creado tres años después, en 1904. La representación bahiense en el Congreso fue de carácter individual y no gremial, como sucedió en los casos de Mendoza o Corrientes. 
su aplicación no solucionó los problemas de plagio, de traducción y de uso no autorizado que continuaban denunciándose con frecuencia.

En Bahía Blanca, de hecho, las acusaciones en este sentido afectaron fundamentalmente a las empresas teatrales y también, en menor medida, a la impresión de obras literarias. La prensa local, sin embargo, no prestó especial consideración a este asunto y se limitó a publicar unos pocos artículos de carácter general en 1910 y 1922 y una breve nota informativa en 1926, cuando el diputado nacional Leopoldo Bard presentó su proyecto de reforma de la legislación vigente. No sorprende que en el año del centenario de la Revolución de Mayo haya sido, una vez más, el periódico socialista Hoja del Pueblo quien asumiera la representación de la protección del trabajo intelectual. Con motivo de una editorial aparecida en el diario porteño La Prensa, el periódico bahiense expresó mediante una réplica enérgica la necesidad de proteger los "productos del ingenio" como parte de un programa de fomento del "progreso científico y literario" de la nación. Así, su reclamo focalizaba sobre lo imperioso de desarrollar una suerte de proteccionismo intelectual que favoreciera lo argentino frente a lo importado:

Si la nación argentina está ávida de producciones científicas y artísticas europeas, que las utilice; pero que las pague: de esta manera se encarecerá lo extranjero y se establecerá el estímulo para la producción nacional. [...] Aquí donde no se cultivan las letras, la propiedad literaria dará valor á la producción nacional; así como los derechos de importación es quien permite que se fabrique y expenda á buen precio el azúcar argentino.

En lo que toca al teatro ya se palpan los resultados de esa protección al robo. Las empresas teatrales toman lo extranjero que no les obliga a ningún pago de derecho de autor y solo en casos excepcionales lleva á escena obras nacionales hay para ellos una conveniencia que se traduce en una deserción total por parte de nuestros escritores reducidos á cero por la competencia de lo escrito en otros países... ${ }^{52}$

A pesar de que más adelante se mencionaba el derecho de los hombres a "vivir de su trabajo", lo cierto es que el artículo no enfatizaba la dimensión laboral de la cuestión sino que se enfocaba sobre la creación de las condiciones de posibilidad para el desarrollo de una "industria" literaria nacional equipa-

52 “Propiedad intelectual”, Hoja de Pueblo, 2 de julio de 1910, p. 2. 
rable a otras, como la del azúcar. Subsidiariamente, la fundamentación recurría de nuevo a argumentos de índole moral que se sostenían sobre la demanda de jerarquización y de reconocimiento de la dignidad de la labor intelectual.

La nota publicada por El Atlántico en 1922 -en respuesta, en este caso, a La Nación-, aunque también pretendía legitimar el trabajo de los "intelectuales" y la poca consideración que les prodigaba la sociedad bahiense, se inscribía en la tradición de un discurso romántico que, desde fines del siglo anterior, denunciaba en las páginas de los periódicos y revistas el "materialismo" local y la incomprensión endémica que afectaba la relación de los artistas con su público. La falta de una remuneración justa era presentada aquí no como un derecho laboral vulnerado sino como un mal intrínseco a la misión intelectual, desactivando, de este modo, todo proyecto transformador con carices gremiales.

La aprobación de la Ley de jubilaciones 11289 y sus repercusiones sobre los periodistas y los gráficos tuvo, a diferencia de la anterior, una considerable resonancia en los medios locales. Si bien tanto la prensa comercial $-E l$ Atlántico, El Siglo y La Nueva Provincia-como la socialista -Nuevos Tiempos-, se interesaron en las implicancias de la nueva legislación, su actitud frente a la extensión de los beneficios jubilatorios a los obreros del periodismo fue sustancialmente diversa. Mientras parte de la primera señaló la importancia del reconocimiento profesional que suponía el artículo 1 de la norma al establecer la creación de una caja de previsión social específica para el sector, la segunda adhirió al discurso de Juan B. Justo y denunció que "es una ley de favor y corrupción en la que ha tenido mucha arte el gremio de los periodistas de gran influencia en las esferas gubernativas". ${ }^{53}$ Justo proponía una aplicación parcial que incorporara sólo a los "trabajadores que no pueden ganarse el sustento en su vejez y tienen que recurrir a la caridad pública". Los periodistas, por el carácter intelectual de su labor y por sus vínculos con el poder, eran así implícitamente distinguidos de los obreros manuales y se cuestionaba su inclusión en las categorías definidas por la legislación.

Distinta fue la posición asumida por los demás diarios: mientras, sin ocuparse en demasía de lo relativo al periodismo, El Siglo asumía la protección de las ganancias y la "libertad de contratación" de las patronales y $\mathrm{La}$ Nueva Provincia se centraba en las polémicas referidas a la aplicabilidad y la

53 "La ley de jubilaciones parciales. Lo que opina el Dr. Justo", Nuevos Tiempos, 13 de febrero de 1924 , p. 3 . 
constitucionalidad de la ley, El Atlántico le dedicaba varios artículos a la jubilación de los periodistas y a la actitud asumida por el Círculo de la Prensa. Con la ley quedaban "satisfechas, en la parte, las aspiraciones legítimas" de los trabajadores de la prensa para quienes la jubilación "no era una concesión graciosa del estado, sino el reconocimiento expreso de los deberes del cuerpo social para los individuos que, cumplida la labor activa, llegan por el desgaste orgánico, a un periodo en que no les es posible continuar cooperando como factores positivos, en la lucha por el mejoramiento común". ${ }^{54}$

Así, resulta comprensible que, en oposición a la huelga general que las agrupaciones obreras declararon en protesta contra la implementación de la norma, los círculos de la prensa porteño, platense y local manifestaran rápidamente su adhesión y se aprestaran a encabezar el registro de periodistas para ofrecerlo a la Caja de Previsiones. También se explica el interés sostenido de El Atlántico por las nuevas disposiciones legales si tenemos en cuenta que, para ese momento, en sus filas se encontraban periodistas como Aurelio Arturo Oliveros, Francisco Rosito y Pedro Pitiot, que hacían de la escritura su medio de vida, que habían intervenido activamente -en el caso de los dos últimos- en la conformación del Círculo de 1919 y que se sumaron en 1924 al Círculo de periodistas en funciones.

Las opiniones vertidas a propósito del conflicto jubilatorio permiten entender también los posicionamientos y las omisiones referidas al anteproyecto de estatuto profesional presentado por el diputado radical personalista $^{55}$ Víctor Juan Guillot en 1926. A decir de Daniel Parcero, a pesar de que no llegó a ser sancionado, el texto del legislador entrerriano ya contenía los puntos fundamentales de la reglamentación que sería finalmente aprobada en 1944, dado que proponía un régimen de protección legal por el cual se establecían sueldos mínimos para los periodistas y se les otorgaba estabilidad laboral regulando las causas y las condiciones de los despidos. Es elocuente que en Bahía Blanca el proyecto de Guillot no suscitara más comentarios que los de su correligionaria, La Nueva Provincia; los otros medios guardaron un significativo silencio, aun cuando la transcripción periódica de las sesiones

54 “Jubilación de periodistas. Hacia el seguro social", El Atlántico, 12 de enero de 1924, p. 1.

${ }_{55}^{5}$ La escisión entre personalistas y antipersonalista al interior de la UCR, partido gobernante desde 1916, se consumó en la asamblea partidaria realizada en 1924 en el teatro Coliseo. Mientras los primeros se nuclearon en torno a Hipólito Yrigoyen y su liderazgo indiscutido, los segundos reivindicaban la figura de Leandro Alem y la carta orgánica de 1892 para oponerse a la jefatura carismática del ex presidente (Persello, 2002, pp. 67-74). 
de la Cámara de Diputados de la nación en sus páginas permite conjeturar que estaban al tanto del acontecer parlamentario. En este sentido, puede inferirse que la posición crítica de El Siglo y El Atlántico respecto del accionar del radicalismo yrigoyenista durante los últimos comicios (Llull, 2005) y la franca oposición de Nuevos Tiempos como representante del socialismo, impidieron que se ocuparan seriamente del estatuto, llevándolos a privilegiar, por el contrario, el tratamiento de los conflictos entre los miembros de la Cámara y la postergación de los inicios del año legislativo. La Nueva Provincia, en cambio, transcribió los términos del anteproyecto y expresó de forma explícita su apoyo a través de un artículo en que se resaltaba el "alto espíritu de justicia y de solidaridad social" que animaba al autor. ${ }^{56}$ Recurriendo a los tradicionales argumentos que sostenían el carácter laboral de las tareas intelectuales, agregaba que la nueva ley favorecería también a las empresas informativas ya que "no sólo mejorará la situación económica de los periodistas, sino que favorecerá el cumplimiento de un proceso selectivo en el seno de este importante gremio". ${ }^{57}$

Como hemos visto hasta aquí, los obstáculos que impidieron la formación de una organización gremial representativa de los periodistas y escritores se hicieron evidentes en la limitada atención que se prestó durante el periodo a los avances y propuestas legislativas destinados a proteger y reglamentar el ejercicio profesional de la labor intelectual. La preeminencia de una visión romántica que concebía el periodismo como una "misión" y al escritor como un mártir del pensamiento, y las dimensiones reducidas del mercado que restringían su autonomía laboral, confabularon contra la estabilidad de las entidades y atenuaron el interés por la defensa de los derechos corporativos. Si bien la cobertura que los debates al respecto tuvieron en los medios dependió en gran medida de la composición del staff periodístico o de la filiación ideológico-partidaria de cada uno de ellos, lo cierto es que, en la mayoría de los casos, la atención que les prestaron fue sumamente reducida-cuando no inexistente- en comparación con el interés suscitado por temáticas más abstractas o principistas.

La preocupación por la libertad de expresión y el "apostolado" de la prensa fue, de hecho, permanente y puede rastrearse desde fines del siglo XIX y hasta la última etapa de nuestro periodo. En 1926, por ejemplo, mientras

\footnotetext{
56 "Los trabajadores del periodismo", La Nueva Provincia, 19 de julio de 1926, p. 2.

57 "Los trabajadores del periodismo", La Nueva Provincia, 19 de julio de 1926, p. 2.
} 
Guillot presentaba su proyecto en la Cámara baja, el incendio de la redacción de un periódico de General Villegas (provincia de Buenos Aires), supuestamente iniciado por la policía, suscitó la indignación de El Atlántico y de Nuevos Tiempos. Lejos de ser un caso aislado, todos los años se recogían en la prensa bahiense violaciones análogas a este derecho constitucional perpetradas, por lo general, en el interior del país, en localidades como Santa Rosa, Azul, Chajarí, entre muchas otras. Este problema, antes que los relativos a la condición laboral de los periodistas, constituía el eje de las preocupaciones en el territorio de las provincias donde las autoridades políticas y policiales continuaban ejerciendo la censura, incluso violenta, sobre los medios de prensa opositores. El proyecto de regulación de la libertad de imprenta presentado por el diputado Tomás Jofré a la Cámara legislativa bonaerense que provocó la protesta generalizada de los diarios y periódicos locales, constituyó una evidencia indiscutible del alcance y de la pervivencia de estas prácticas en el espacio provincial. ${ }^{58}$ Con motivo de los "excesos de ciertos diarios de la campaña", ${ }^{59}$ Jofré proponía reglamentar los delitos de calumnias, injurias y ofensas a la moralidad pública estableciendo condenas que incluían desde multas hasta penas de prisión. A diferencia de lo sucedido a propósito de los proyectos mencionados en párrafos anteriores, la reprobación de la propuesta fue general en el periodismo local y provincial y en sus respectivos círculos: las opiniones referidas al respeto de los principios del liberalismo en materia intelectual no variaban en función de las posiciones políticas y su transgresión bastaba para movilizar conjuntamente al sector.

\section{CONCLUSIONES}

Analizar el proceso de profesionalización de la escritura, y en especial del periodismo, en Bahía Blanca a principios de siglo, supone reconsiderar las temporalidades a la luz de la especificidad de la dimensión local y de las particularidades que distinguían a una ciudad intermedia y en crecimiento de las grandes urbes nacionales e internacionales. Lo que Ramos definió para

${ }^{58}$ Las preocupaciones referidas a la regulación de la libertad de prensa atravesaban no sólo al periodismo, sino a los ámbitos parlamentarios y académicos. Para un tratamiento exhaustivo del tema desde una perspectiva contemporánea, puede consultarse, entre otros, Durá (1918).

59 "Libertad de prensa", La Nueva Provincia, 20 de mayo de 1914, p. 1. 
el caso latinoamericano como una modernización desigual, adquirió nuevos sentidos en regiones alejadas de la capital donde la posibilidad de sustentarse económicamente por parte de los productores intelectuales disminuía frente a un mercado editorial débil y un público escaso. En otras ocasiones, hemos explorado los modos en que se fue construyendo la imagen del intelectual como colectivo y los mecanismos representacionales de diferenciación interna entre poetas y periodistas. En el presente artículo examinamos de qué manera la emergencia de esta identidad propia se concretó en la formación de las primeras organizaciones profesionales que pretendieron aglutinar a los trabajadores de la pluma bajo la figura del periodismo, convirtiéndose en nuevos espacios de sociabilidad donde la defensa de los intereses laborales se combinó, en ocasiones, con cierto espíritu de distinción que inició la unión de sus miembros sobre la convicción de la excepcionalidad de la actividad letrada. Si bien la aparición de dichas asociaciones supuso un rasgo moderno al reconocer el carácter laboral de las actividades intelectuales, lo cierto fue que también en este aspecto el proceso mostró rápidamente sus limitaciones. La heterogeneidad interclasista que implicaba la coexistencia -no siempre armónica- entre empresarios y redactores y la inclusión de profesionales de otras áreas que ejercitaban la escritura por afición, dificultó la acción conjunta de las sociedades en la defensa de los derechos laborales y les otorgó, en ocasiones, un perfil aristocrático y una vida efímera.

Estas tensiones entre las incipientes aspiraciones profesionales y el carácter meramente social que adquirieron las entidades, permearon también a nivel local los debates en torno a la profesión y a la misión de la prensa que tuvieron lugar durante el periodo. La escasa cobertura informativa que tuvieron en las hojas periódicas bahienses los proyectos legislativos abocados a la promoción de la jubilación de los trabajadores de la prensa (1924), la protección de la propiedad literaria (1926) y, sobre todo, el Estatuto del Periodista (1926), dio cuenta de una agenda desigual de preocupaciones que priorizaba problemáticas de orden general y principista -como la moralidad de la noticia o la defensa de la libertad de imprenta- frente a otras de tipo gremial. Por supuesto, la imposibilidad de consolidar sociedades representativas y duraderas durante las primeras décadas del siglo no era síntoma de inmovilidad y estancamiento. Por el contrario, la mera existencia de las experiencias aquí descritas evidenciaba la transformación de las condiciones y la manera de concebir las tareas intelectuales, así como la presencia de grupos que se reconocían a sí mismos principalmente como periodistas. Asimismo, el devenir 
de los distintos círculos y las discrepancias entre ellos traslucían una paulatina diferenciación interna del sector fundada en los intereses diversos que separaban cada vez más a los trabajadores de la escritura de los propietarios de los medios periodísticos. No obstante ello, la creencia en una misión histórica compartida y la convicción de formar parte de una elite de hombres-espiritu -en palabras de Estanislao Zeballos-que los distinguía cualitativamente de los obreros manuales, impidió, junto a las limitadas condiciones materiales del mundo cultural local, la materialización de esta naciente conciencia profesional en una experiencia asociativa perdurable que lograra articular las demandas de los escritores de la prensa.

\section{LISTA DE REFERENCIAS}

$1^{\circ}$ Congreso de la Prensa Argentina (1901). Buenos Aires: Círculo de la Prensa.

Agesta, M. de las N. (2013a). Entre la unión y la diferencia. Las representaciones de los intelectuales en las revistas culturales de Bahía Blanca en las primeras décadas del siglo xx. Antiteses, VI(12), 310-335. DoI: http://dx.doi.org/10.5433/1984-3356.2 013v6n12p367

Agesta, M. de las N. (2013b). Los recorridos de la cultura. Operadores, intermediarios y tránsitos culturales en el periodismo bahiense de principios del siglo xx. En M. N. Cernadas de Bulnes y P. A. Orbe (comps.), Itinerarios de la prensa: cultura política y representaciones en Bahía Blanca, siglo xx (pp. 67-93). Bahía Blanca: Ediuns.

Agesta, M. de las N. (2016). Páginas modernas. Revistas culturales, transformación social y cultura visual en Bahía Blanca, 1902-1927. Bahía Blanca: Ediuns.

Agüero, A. C. y García, D. (eds.) (2010). Culturas interiores. Córdoba en la geografía nacional e internacional de la cultura. La Plata: Al Margen.

Agulhon, M. (2009). El círculo burgués. La sociabilidad en Francia, 1810-1848. Buenos Aires: Siglo XXI Editores.

Altamirano, C. y Sarlo, B. (1997). Ensayos argentinos. De Sarmiento a la vanguardia. Buenos Aires: Ariel.

Ansaldi, W. (1996-1997). Una modernización provinciana: Córdoba, 1880-1914. Estudios, 7 y $8,51-80$.

Auza, N. T. (2000). Un indicador de la cultura bonaerense. El periodismo de 1877 a 1914. Investigaciones y Ensayos, 50, 101-128.

Berman, M. (2006). Todo lo sólido se desvanece en el aire; la experiencia de la modernidad. Madrid: Siglo Veintiuno Editores. 
Bourdieu, P. (1995). Las reglas del arte. Génesis y estructura del campo literario. Barcelona: Anagrama.

Brunner, J. J. (1986). La modernidad y el futuro de América Latina. Santiago de Chile: Flacso.

Cane, J. (2007). “Trabajadores de la pluma”, periodistas, propietarios y Estado en la transformación de la prensa argentina, 1935-1945. En M. L. da Orden y J. C. Melón Pirro (comps.), Prensa y peronismo. Discursos, prácticas y empresas, 1943-1958 (pp. 2946). Rosario: Prohistoria.

Cernadas, M. N. (1994). Estanislao Zeballos. Una visión optimista de la Bahía Blanca de fines del siglo XIX. Buenos Aires: Facultad de Derecho y Ciencias Sociales-Instituto de Historia de la Universidad Católica Argentina.

Cernadas de Bulnes, M. (1995). La idea de progreso en la vida cotidiana de Bahía Blanca de fines del siglo xIx: nuevas formas de sociabilidad (pp. 35-62). En M. Cernadas de Bulnes, N. Buffa de Bottaro y A. S. Eberle, Estudios sobre inmigración III. Bahía Blanca: CER-Depto. de Humanidades-uns.

Círculo de la Prensa. Memoria de los trabajadores realizados durante el ejercicio de 1904-1905 (1905). Buenos Aires. Biblioteca Bernardino Rivadavia, Bahía Blanca.

Durá, F. (1918). Libertad constitucional y licencia práctica de la prensa. Buenos Aires: Imprenta de José Tragant.

Estatutos y reglamentos del Círculo de la Prensa de Bahía Blanca (1904). Bahía Blanca: Tipografía Galiani. Biblioteca Bernardino Rivadavia, Bahía Blanca.

Estatutos y reglamentos del Círculo de la Prensa reformados en Asamblea General Extraordinaria (1902). Buenos Aires. Biblioteca Bernardino Rivadavia, Bahía Blanca.

Fernández, Juan Rómulo (1943). Historia del periodismo argentino. Buenos Aires: Librería Perlado Editores.

Fiorucci, F. (coord.) (2013). Dossier: Los otros intelectuales: curas maestros, intelectuales de pueblo, periodistas y autodidactas. Prismas, 17, 165-236.

Freinkel, P. (1993). Diccionario biográfico bahiense. Buenos Aires: Letra Viva.

Galván Moreno, C. (1944). El periodismo argentino. Buenos Aires: Claridad.

García Canclini, N. (2005). Culturas híbridas. Estrategias para entrar y salir de la Modernidad. Buenos Aires: Paidós.

Gayol, S. (2008). Honor y duelo en la Argentina moderna. Buenos Aires: Siglo XXI Editores.

González Coll, M. M. et al. (1981). Homenaje al Colegio Nacional de Bahía Blanca en su 75a aniversario 1906-1981. Bahía Blanca: Panzini Hnos. 
Grisendi, E. (2014). Los "escritores de provincia” como tema. Mediadores culturales y circuitos literarios "periféricos" (Córdoba, 1940-1960). Trabajo y Sociedad, 22, 273-284.

Heredero Clar, E. y Abad Martínez F. (eds.) (1928). Los españoles en el Centenario de Bahía Blanca. Bahía Blanca: Panzini Hnos.

Igoillo Dantiacq, A. S. (30 de abril de 1928). El libro en Bahía Blanca. Arte y Trabajo, 13(159), s. p. Hemeroteca de la Biblioteca Bernardino Rivadavia, Bahía Blanca.

Laera, A. (2008). Cronistas, novelistas: la prensa periódica como espacio de profesionalización en la Argentina (1880-1910). En J. Myers (ed.), Historia de los intelectuales en América Latina. I. La ciudad letrada, de la conquista al modernismo (pp. 495-522). Buenos Aires: Katz.

Laguarda, P. y Fiorucci, F. (eds.) (2012). Intelectuales, cultura y política en espacios regionales de Argentina (siglo xx). Rosario: Prohistoria Ediciones/Universidad Nacional de La Plata.

Laurent, V. (1997). Cien años de historia política. Elites y poder en Bahía Blanca (1886-1986) (Tesis de doctorado inédita). Universidad Nacional del Sur, Bahía Blanca.

Libro Genealógico Familia PITIOT en Francia, España y Argentina (2011). PitiotGenealogie, Archivo Pitiot Bahía Blanca-Argentina. Recuperado de pitiotgenealogie.com/genealogia/libro-genealogico-familia-pitiot-en-francia-espan\%CC\%83a-y-argentina/

Llop Tomé, J. M. (dir.) (1999). Ciudades intermedias y urbanización mundial. Adjuntament de Lleida: Unesco/UiA/Ministerio de Asuntos Exteriores.

López Pascual, J. (2012). ¿Los artistas trabajan? Estado y profesionalización de la labor intelectual durante el peronismo (Bahía Blanca, 1946-1955). Ponencia presentada en las Ix Jornadas de Investigadores del Depto. de Historia-Facultad de Humanidades, Mar del Plata, Argentina.

López Pascual, J. y Agesta, M. de las N. (2013). Páginas de cultura. Las revistas culturales en Bahía Blanca durante el siglo xx. En M. N. Cernadas de Bulnes y P. A. Orbe (comps.), Itinerarios de la prensa: cultura política y representaciones en Bahía Blanca, siglo xx (pp. 47-63). Bahía Blanca: Ediuns.

Losada, L. (2006). Sociabilidad, distinción y alta sociedad en Buenos Aires: los clubes sociales de la elite porteña (1880-1930). Desarrollo Económico-Revista de Ciencias Sociales, XLV(180), 547-572.

Llull, L. (2005). Prensa y politica en Bahía Blanca. La Nueva Provincia en las presidencias radicales, 1916-1930. Bahía Blanca: Ediuns.

Marcilese, J. B. (2013). Tensiones y conflictos en la prensa bahiense durante el primer peronismo. En M. N. Cernadas de Bulnes y P. A. Orbe (comps.), Itinerarios de la 
prensa: cultura política y representaciones en Bahía Blanca, siglo xx (pp. 191-223). Bahía Blanca: EdiUNS.

Marcilese, J. B. y Tedesco, M. C. (2006). 1906-2006. Club Argentino de Bahía Blanca. Centenario. Bahía Blanca: Club Argentino.

Marco, M. A. de (2006). Historia del periodismo argentino: desde los orígenes hasta el centenario de Mayo. Buenos Aires: Educa.

Martínez Zuccardi, S. (2012). En busca de un campo cultural propio. Literatura, vida intelectual y revistas culturales en Tucumán (1904-1944). Buenos Aires: Corregidor.

Martínez, A. T. (2013). Cultura, sociedad y poder en Argentina. La modernización periférica de Santiago del Estero. Santiago del Estero: EDUNSE.

Ortiz, R. (2000). América Latina. De la modernidad incompleta a la modernidad-mundo. Nueva Sociedad, 166, 44-61.

Paglialunga de Tuma, M., Bermejo Hurtado, H. y Blanco de Anta, A. M. (1982). Los primeros textos literarios impresos en Bahía Blanca (poetas y narradores). Cuadernos del Sur, 15, 151-175.

Parcero, D. (2010). Los trabajadores de prensa, ladrilleros del periodismo: organización y lucha de los periodistas sindicalizados: 1891-2010. Buenos Aires: Corregidor.

Pasolini, R. (2006). La utopía de Prometeo. Juan Antonio Salceda, del antifascismo al Comunismo. Tandil: Universidad Nacional del Centro.

Persello, A. V. (2002). Los gobiernos radicales: debate institucional y práctica política. En R. Falcón (dir.), Nueva historia argentina. T. 6. Democracia, conflicto social y renovación de ideas (1916-1930) (pp. 59-99). Buenos Aires: Sudamericana.

Rama, A. (2004). La ciudad letrada. Santiago de Chile: Tajamar.

Ramos, J. (2003). Desencuentros de la modernidad en América Latina. Literatura y política en el siglo XIX. México: Fondo de Cultura Económica.

Ribas, D. I. (2008). Del fuerte a la ciudad moderna. Imagen y autoimagen de Bahía Blanca. (Tesis inédita de doctorado). Universidad Nacional del Sur, Bahía Blanca.

Rivera, J. B. (1998). El escritor y la industria cultural, Buenos Aires: Atuel.

Silva, H. (1988). Economía. En F. Weinberg (dir.), Historia del sudoeste bonaerense (pp. 229-243). Buenos Aires: Plus Ultra.

Vignoli, Marcela (2015). Sociabilidad y cultura política. La Sociedad Sarmiento de Tucumán, 1880-1914. Rosario: Prohistoria.

Viñas, D. (1995). Literatura argentina y política. De los jacobinos porteños a la bohemia anarquista. Buenos Aires: Santiago Arcos.

Weinberg, F. (1988). Sociedad. En F. Weinberg (dir.), Historia del sudoeste bonaerense (pp. 259-274). Buenos Aires: Plus Ultra. 


\section{OTRAS FUENTES}

Archivo Familia Pitiot, Bahía Blanca.

Archivo de La Nueva Provincia, Bahía Blanca.

Biblioteca Bernardino Rivadavia, Bahía Blanca.

Hermeroteca de la Biblioteca Bernardino Rivadavia, Bahía Blanca.

\section{Bibliografía}

Williams, R. (2001). Cultura y sociedad, 1780-1950. Buenos Aires: Nueva Visión.

\section{Hemerografía}

Bahía Blanca.

El Atlántico.

El Censor.

El Comercio.

El Heraldo.

El Proletario.

El Siglo.

Hoja del Pueblo.

La Nueva Provincia.

Nuevos Tiempos. 